\title{
The transition from No Net Loss to a Net Gain of biodiversity is far from trivial
}

J. W. BULL and S. BROWNLIE

\begin{abstract}
The objectives of No Net Loss and Net Gain have emerged as key principles in conservation policy. Both give rise to mechanisms by which certain unavoidable biodiversity losses associated with development are quantified, and compensated with comparable gains (e.g. habitat restoration). The former seeks a neutral outcome for biodiversity after losses and gains are accounted for, and the latter seeks an improved outcome. Policy-makers often assume that the transition from one to the other is straightforward and essentially a question of the amount of compensation provided. Consequently, companies increasingly favour Net Gain type commitments, and financial institutions make lending conditional on either objective, depending on the habitat involved. We contend, however, that achieving Net Gain is fundamentally different to achieving No Net Loss, and moving from one to the other is less trivial than is widely realized. Our contention is based on four arguments: (1) the two principles represent different underlying conservation philosophies; (2) ecological uncertainties make it difficult to know where the threshold between No Net Loss and Net Gain lies; (3) different frames of reference are more or less appropriate in evaluating the ecological outcomes, depending on the principle chosen; and (4) stakeholder expectations differ considerably under the two principles. In exploring these arguments we hope to support policymakers in choosing the more appropriate of the two objectives. We suggest that financial institutions should provide greater clarity regarding the explicit requirements for each principle. We conclude by highlighting questions of relevance to this topic that would benefit from focused research.
\end{abstract}

Keywords Biodiversity offset, development impacts, frame of reference, mitigation hierarchy, net gain, net positive, no net loss, uncertainty

\section{Introduction}

The challenge of finding mechanisms that conserve bio1 diversity alongside economic development is a priority

\footnotetext{
J.W. BulL (Corresponding author) Department of Food and Resource Economics \& Centre for Macroecology, Evolution and Climate, University of Copenhagen, Rolighedsvej 23, 1958 Copenhagen, Denmark E-mail jwb@ifro.ku.dk

S. Brownlie deVilliers Brownlie Associates, Claremont, South Africa

Received 2 April 2015. Revision requested 21 May 2015.

Accepted 8 July 2015. First published online 10 November 2015.
}

for humanity (Baillie et al., 2004; Mace et al., 2005). One emerging principle that shows promise in this regard is that of No Net Loss. The objective is to permit development whilst retaining overall levels of biodiversity, by applying a mitigation hierarchy (e.g. avoid, minimize, restore, offset; BBOP, 2012a) in relation to negative impacts of development on nature. Despite the technical difficulties that arise in implementation (Bull et al., 2013a; Gardner et al., 2013) and the controversy surrounding the logic underpinning No Net Loss (Apostolopoulou \& Adams, 2016), the principle is increasingly well established in international policy (e.g. Madsen et al., 2010; Tucker et al., 2013) and corporate practice (Rainey et al., 2015). It is consequently a topic of ongoing research interest.

In 2014 a conference was held on this topic: To no net loss of biodiversity and beyond (BBOP, 2014). Throughout, there was much talk of aiming for a net gain in biodiversity, as a superior goal to No Net Loss. Net Gain is already reflected both in relation to project finance (e.g. the International Finance Corporation specifies the need for a net gain in biodiversity in critical habitat as a lending requirement; IFC, 2012) and in corporate sustainability strategies (e.g. Net Positive Impact commitments; Rainey et al., 2015). The choice of a commitment to positive Net Gain over the more neutral No Net Loss is desirable to many stakeholders. In theory it should represent a better outcome for biodiversity conservation, whilst aligning with the Aichi targets (CBD, 2010) and presumably the objectives of biodiversity stakeholders. Furthermore, it is appealing to businesses seeking a positive strategic message over a neutral one.

There has been scant commentary, however, on the implications of transitioning from one objective to the other. Net Gain is in some cases simply described as 'No Net Loss plus' (GN107, guidance note to the International Finance Corporation's Performance Standard 6; IFC, 2012), or where the 'biodiversity gains exceed a specific set of losses' (BBOP, 2012b). Our view is that this transition is poorly understood but presents significant challenges, some of which we outline here.

It seems to be a common assumption that the difference between achieving the two outcomes is almost trivial (e.g. if a development clears 100 trees but the developer plants a stand of 100 trees nearby then there is arguably no net loss; if the developer plants 101 trees they have achieved a net gain). We have heard this assumption implied throughout the No Net Loss conference and elsewhere, although not in the academic literature. The perceived triviality of such a transition may partly explain corporate eagerness to make 
positive rather than neutral commitments. However, the differences between the two policy objectives are more significant than is currently widely appreciated. The challenges we explore here illustrate the complexities of the transition from No Net Loss to Net Gain.

Note that when we refer to biodiversity value, it is intended in this context to mean a measure of any component of biodiversity that has intrinsic use or cultural significance for one or more stakeholders, and any component that forms the basis of impact assessment and mitigation efforts, including biodiversity offsetting.

\section{The transition from No Net Loss to Net Gain}

\section{Distinct underlying conservation philosophies}

Whether or not either of the policy objectives can be met depends explicitly on their scope and what they are intended to achieve by when (ten Kate \& Crowe, 2014). At its simplest, to achieve No Net Loss, loss of biodiversity values must be fully compensated by commensurate gains in those values. To achieve the more positive objective of a Net Gain, the biodiversity status quo must be improved, either by overcompensating for loss in the biodiversity values affected, or by ensuring no net loss in those values and then providing additional gains in other biodiversity values. The latter would involve so-called out-of-kind biodiversity compensation. Out-of-kind compensation is not synonymous with a Net Gain objective but is one way of attempting to achieve it.

The concept of 'like for like or better' exchanges is a widely held tenet of No Net Loss policy and is expressed in key standards (e.g. BBOP, 2012a; IFC, 2012). In certain contexts gains in a biodiversity component other than that affected, but of higher conservation value, may be permitted to count towards achieving No Net Loss/Net Gain (so-called trading up), rather than requiring like for like gains. Tensions exist between the like for like and the '.. or better' concepts; the former adheres predominantly to scientific metrics for impact-compensation exchanges, whereas the latter moves into the realm of societal value judgements, for which there is no easy metric to convert losses of one type of biodiversity to gains in another. In some cases the former may be possible using relatively straightforward species- or habitat-based metrics, whereas the latter may require a better understanding of (and metrics that capture) ecological processes. This shift exacerbates the complexity of determining when policy goals have been reached.

Occasionally the wisdom of strict like for like constraints is challenged (Habib et al., 2013), as conservation objectives may not always be best served through in-kind exchanges. Using an example of ecological compensation in relation to oil and gas activity in north-west Uzbekistan (Bull et al., 2013b), direct losses primarily comprise clearance of

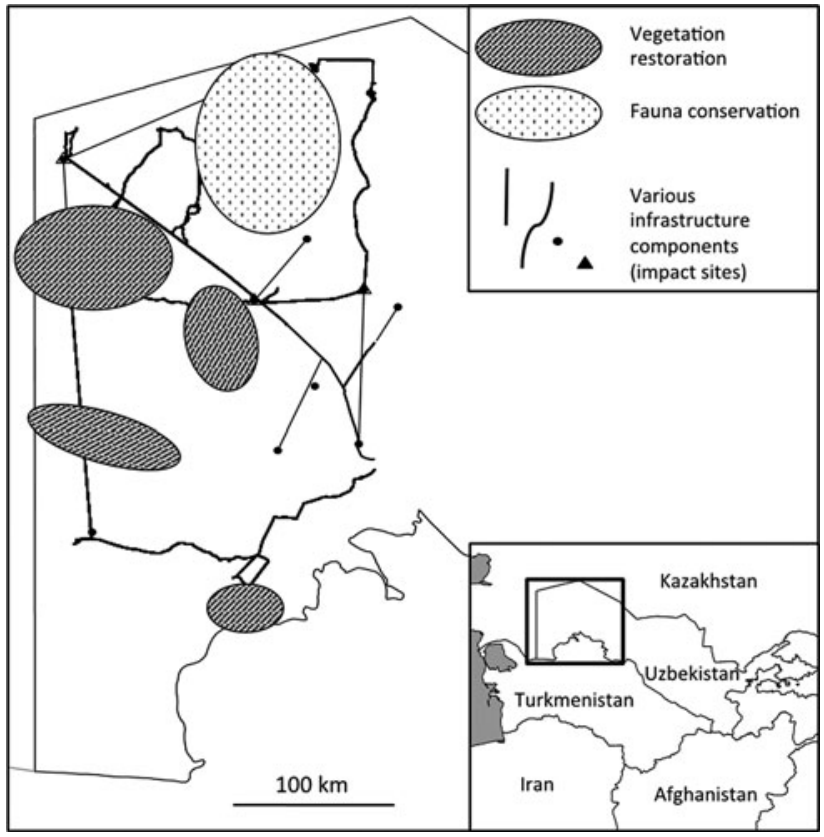

FIG. 1 Extant oil and gas industry infrastructure in north-west Uzbekistan, alongside potentially optimal regions for biodiversity offsets. Infrastructure, mapped using data collected by Jones et al. (2014), is known to affect fauna and flora negatively in this region. Potential biodiversity offset sites (displayed here schematically) were determined based on quantitative analyses undertaken by Bull (2014); optimum sites were identified both for like-for-like offsets (vegetation restoration) and for out-of-kind offsets (fauna protection).

vegetation for infrastructure (Jones et al., 2014). A strict framework for full ecological compensation here could potentially require restoration of vegetation across the landscape (Fig. 1). However, the vegetation cleared during the past c. 40 years for oil and gas represents c. $0.2 \%$ of the regional habitat by area, and therefore spending funds on its restoration or protection would not necessarily deliver material gains for conservation. Conversely, funding the creation and operation of aggregated areas where poaching pressure on threatened fauna was removed, with habitat protection as an incidental outcome, could represent a more valuable gain for biodiversity conservation. The latter approach is out of kind, as losses in grassland would be traded for gains in fauna conservation, but could deliver an overall gain from the perspective of conserving priority biodiversity in Uzbekistan (i.e. would satisfy the '... or better' condition). Comparable arguments have been made elsewhere, for example for caribou in Canada (with offsets that target caribou as an out of kind priority species in exchange for vegetation losses; Habib et al., 2013).

In the Uzbek case if no net loss of specific biodiversity components were the intention of policy-makers (as for wetlands in the USA, for example) then the developer might be obliged to carry out an equivalent amount of 


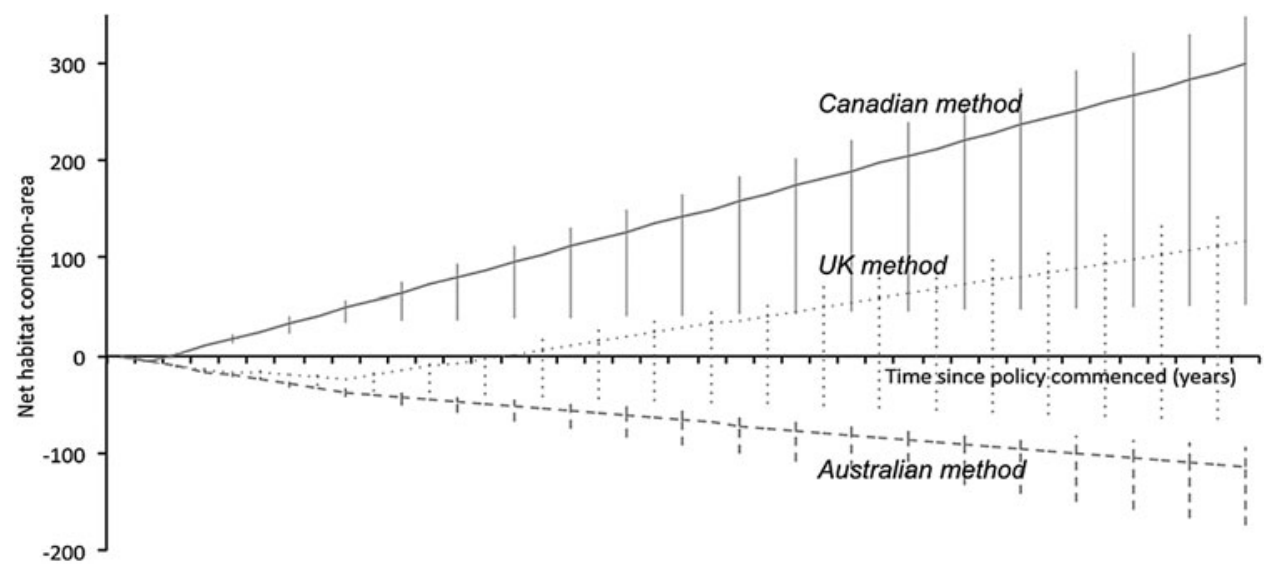

FIG. 2 Simulated net condition-area trajectories for Uzbek scrub habitat, achieved under three biodiversity offset methodologies, for the case study of oil and gas infrastructure in north-west Uzbekistan (Fig. 1). The condition-area of any one patch of habitat is the patch area $\times$ the condition of the patch (normalized between o and 1). Vertical lines indicate uncertainty bounds. The methodologies applied (for illustration) are fish habitat compensation (Canada), biodiversity offsetting pilot (UK) and native grassland compensation (Victoria, Australia). Net outcome is calculated as the condition-area of habitat gains from offset sites minus the condition-area of habitat losses as a result of development activities. When net outcome $=0$, No Net Loss is achieved; when net outcome $>0$, Net Gain is achieved. (Adapted from Bull et al., 2014a)

habitat restoration, or restore a bit more than was lost to achieve a net gain. However, the intention is to achieve net conservation gain, making a stronger case for taking a more flexible approach, targeting higher priority biodiversity (i.e. fauna species, provided that credible exchange rules are in place). This example emphasizes a possible distinction between the two policy objectives: that No Net Loss could be used to target predominantly 'like' biodiversity and maintenance of existing biodiversity trajectories, whereas Net Gain may aim to achieve gains for conservation overall using more 'out of kind' exchanges. The transition from the former to the latter can represent a fundamental shift in philosophy, away from one in which the prevailing trend in biodiversity is accepted even if that is a decline, and the trajectory is not altered (Gordon et al., 2015), to one in which the commitment is used as a mechanism for reversing biodiversity declines in priority areas for conservation, potentially with more acceptability of out of kind approaches. Such a shift in underlying philosophy becomes particularly important in the context of concerns, held by some, that in No Net Loss policies involving biodiversity offsets 'a dystopian future of continued biodiversity loss is presented as the only alternative' (Apostolopoulou \& Adams, 2016) concerns that may presumably be partly mollified under policies requiring a Net Gain.

According to International Finance Corporation guidelines, where development occurs in critical habitat a net gain in the biodiversity values for which the critical habitat was designated is required to satisfy Performance Standard 6 (IFC, 2012). However, where an environmental impact assessment concludes that there will be no residual impacts on the components relevant to the critical habitat designation, no net loss is effectively already predicted. There is therefore no need to further demonstrate quantitatively that offset measures would achieve No Net Loss, as any such measures (presuming they result in positive outcomes for critical habitat components) could be presumed to meet the Net Gain requirement. This facilitates flexibility in designing enhancement measures (e.g. Rajvanshi et al., 2011) and in such cases apparently obviates the need to further quantify losses and gains.

\section{Uncertainty in achieving no net loss}

Demonstrating that biodiversity gains balance losses is a key element of No Net Loss. However, the relevant calculations are subject to uncertainty and risk in a variety of ways; for example, uncertainty in the success and timing of ecological restoration (Maron et al., 2012), measurement error or vagueness in key terms (Kujala et al., 2013), and uncertainty in the degree to which developers will comply with policy (Bull et al., 2013a). To ensure a neutral outcome, taking account of the uncertainties in project design and implementation, projects generally design compensation measures that create more biodiversity value than is lost, often using project multipliers (Moilanen et al., 2009; Pickett et al., 2013). Multipliers are used to improve confidence levels in achieving neutral or net positive biodiversity outcomes (BBOP, 2012b). The fact that meeting a No Net Loss objective often effectively requires overcompensating for losses means that it is not straightforward to specify how large gains should be in the case of a Net Gain policy objective.

Fig. 2 illustrates the net outcome for biodiversity calculated for the Uzbek case study using biodiversity offset methodologies from various jurisdictions (Bull et al., 2014a). Even 
methodologies that should theoretically lead to an overall outcome of net gain can result in a neutral outcome or even net loss, once uncertainties are taken into account. The analysis by Bull et al. (2014a) considered uncertainty only in terms of error in the measurement and estimation of biodiversity losses (i.e. development impacts) and uncertainty in policy compliance; many other sources of uncertainty exist, which would amplify the divergence in outcomes.

If proving that a No Net Loss objective has been attained requires aiming for a Net Gain in any case, what additional measures would be needed to demonstrate that a Net Gain has been achieved? Either (1) the project must include a well-developed and quantified understanding of all uncertainties associated with the development and compensation measures, which is currently beyond the science, let alone practice, or (2) the additional biodiversity value created is such that there can be almost no question that Net Gain is achieved. Choosing the latter option would rely to some extent upon informed estimation and could have significant cost implications compared to the former; this is not a reason to rule it out but is an important consideration. In cases in which societal value judgements have been incorporated into questionable exchange rules and in which uncertainties are large enough, arguably it is impossible to determine the point at which a given project transitioned from a neutral to a net positive outcome for biodiversity.

\section{Frame of reference}

The outcome of implementing a given conservation policy depends on the ecological baseline against which it is evaluated (Gordon et al., 2011). This is especially relevant to policies with measurable goals as a fundamental characteristic, such as those discussed here. However, the appropriate choice of baseline is not straightforward, and it is possible to specify alternative counterfactuals for evaluation (i.e. dynamic baselines, for alternative scenarios that could have occurred in the absence of the policy being implemented; Ferraro \& Pattanayak, 2006). The baseline and set of plausible counterfactual scenarios used for evaluation can together be called the frame of reference (Bull et al., 2014b).

The choice of reference frame can significantly influence the observed outcome; the same policy leading to the same set of conservation actions can result in net loss, no net loss or a net gain in biodiversity. Some reference frames make achieving certain outcomes improbable (Bull et al., 2014b); for instance, a set of policy-driven compensatory mitigation actions evaluated against a no-development counterfactual could point to a net loss for biodiversity, whereas the same actions evaluated against a business-as-usual counterfactual might always result in a net gain (Gordon et al., 2011; Bull et al., 2014b). The chosen frame of reference embodies decisions about the spatial and temporal scales upon which conservation policy is evaluated, which can materially affect whether No Net Loss or Net Gain objectives are met.

In some respects this point blurs the line between the two policy goals under discussion: the difference between achieving neutrality and net gain could be said to rest upon the frame of reference chosen for evaluation. However, the choice of baseline or counterfactual does not simply alter the conclusions drawn from evaluation, it also influences the incentives for participants in the implementation of the policy, and therefore ultimately their choices, which determine the physical outcomes of the policy (Bull et al., 2014b).

Consequently, specifying either No Net Loss or Net Gain as a policy objective requires specifying the frame of reference to be used in evaluation at both a project and a policy level. However, it may be appropriate in some cases to use different baselines to evaluate the various outcomes. For example, a No Net Loss policy objective implies a desire not to exacerbate declines during development projects, perhaps suggesting evaluation against a no-development counterfactual. Alternatively, a Net Gain objective could imply a desire to halt and reverse biodiversity declines in the landscape, suggesting evaluation against a fixed current baseline. Thus, the transition from one to the other could involve considering a change in the frame of reference against which the conservation policy is evaluated. In turn, any modification of the frame of reference could alter the physical outcomes by altering incentives for those implementing the policy.

\section{Stakeholder perceptions}

There is some opposition to the implementation of both policy objectives, and to related mechanisms such as biodiversity offsetting (e.g. Burgin, 2008; Walker et al., 2009; Curran et al., 2014). Moreover, there is often mistrust amongst public stakeholders in offsetting, which has, for instance, been a barrier to the establishment of such policies in the UK (Gordon et al., 2015).

Part of a company's rationale for choosing a Net Gain commitment over No Net Loss is that the former sends a more positive message. The International Financial Corporation's distinction between neutral compensation requirements for natural habitat where feasible and net gain requirements for critical habitat (IFC, 2012) suggests that the difference between the two is significant, possibly fostering raised expectations of offset performance.

Although it has been shown that biodiversity offsets can improve a company's social licence to operate (Richert et al., 2015), many stakeholders will have less confidence that a company can achieve net biodiversity gains rather than No Net Loss. This, in turn, could engender mistrust. In the case of Rio Tinto, for example, who have committed to a policy of Net Positive Impact (Rainey et al., 2015), we 
contest that, whatever they achieve in practice, many members of the public are unlikely to believe that one of the largest extractive companies is having a net positive impact upon nature. Conversely, by implication, No Net Loss commitments suggest only that a company is cleaning up its mess, which is perhaps a more tenable concept to the nonspecialist. Again, the transition from one policy objective to the other is arguably not trivial if one is much more difficult to argue convincingly in a public forum. The ability or otherwise to convince stakeholders of a company's biodiversity achievements represents material reputational risks.

\section{Discussion}

There are some who regard the policy objectives discussed here as 'a symbolic but illusory goal' (Walker et al., 2009) or would dispute whether either goal represents desirable conservation policy. Challenges to achieving No Net Loss/ Net Gain have been discussed in the literature (Gardner et al., 2013; Bull et al., 2013a), and include difficulties in managing uncertainties (Moilanen et al., 2009), ensuring successful restoration (Maron et al., 2012; Curran et al., 2014), applying appropriate currencies, multipliers and exchange rules (BBOP, 2012b), and avoiding perverse incentives (Gordon et al., 2015). Both policy principles remain controversial (Apostolopoulou \& Adams, 2016). However, the idea that businesses should contribute towards ecosystem restoration and the reversal of biodiversity declines has considerable support (Bayon \& Jenkins, 2010), to the extent that it is included within the Aichi targets (Target 4; CBD, 2010).

We consider the policy objectives of No Net Loss and Net Gain to be laudable. Here, we have examined the implications of and highlighted the differences between the two objectives, contending that there may be practical ramifications arising from choosing one over the other. In many cases, however, achievement of either goal is subject to the same methodological challenges (e.g. baselines for comparison, time-frames, choice of metrics, uncertainty).

Our exploration of the transition from No Net Loss to Net Gain may suggest the approaches are on a continuum: in the simplest case, Net Gain may simply be an extension of No Net Loss, being defined in relation to the same biodiversity values and applying a like for like exchange. However, it may not be the case that one is always required to be a stepping stone towards the other. There are a number of open questions relevant to this topic. They include but are not limited to the following:

- How often designing for No Net Loss incidentally leads to Net Gain, and vice versa;

- The extent to which loss of biodiversity is accepted in exchange for conservation of biodiversity of a higher priority to achieve either No Net Loss or Net Gain, and on what basis;
- The extent to which the transition from No Net Loss to Net Gain is viewed as a continuum, and under what conditions and how frequently it is deemed acceptable to target one set of biodiversity components for the former and a different set for the latter;

- Whether or not Net Gain of biodiversity and Net Gain for conservation are perceived as the same or different objectives (i.e. must Net Gain be defined in relation to societal priorities for conservation?);

- Whether the exchange rules for attaining No Net Loss and Net Gain differ in practice;

- How the two objectives apply with respect to social and cultural benefits and values.

Regardless of one's perspective the transition from No Net Loss to Net Gain requires further debate and research, especially given its importance to policy. The question of whether one is different from the other is relevant to corporate considerations regarding setting and evaluating biodiversity policy and strategy, which is an emerging item on the corporate sustainability agenda (Rainey et al., 2015); to the widespread implementation of the mitigation hierarchy under the International Finance Corporation's Performance Standard 6 guidelines, which require a neutral outcome in certain habitats and a positive one in others (IFC, 2012); and to the development of national policy, as No Net Loss is currently under consideration or revision as a policy principle in a number of jurisdictions (e.g. Madsen et al., 2010; Defra, 2011; Tucker et al., 2013; Poulton, 2014).

The difficulty and feasibility of transitioning from No Net Loss to Net Gain should not be underestimated. We have presented four arguments as to why this is the case: (1) the two principles often represent different underlying philosophies on the part of policy-makers; (2) theoretical and practical sources of uncertainty make it unclear when the transition has occurred; (3) the transition is complicated by the question of whether the same frame of reference is appropriate in both cases; and (4) the two principles are likely to evoke different perceptions and expectations among stakeholders. On the basis of this discussion, we advise the following:

For regulators, policy-makers, consultants, businesses, financial institutions and researchers: distinguishing between No Net Loss and Net Gain as policy principles, recognizing the connection between them but also that they can have fundamental differences; and differentiating between, and defining permissible application of like for like and '...or better' exchanges of biodiversity in relation to specific contexts and desired outcomes.

For regulators and policy-makers: clearly defining the scope of application of either or both policy principles, to inform approaches in practice (i.e. to what does each policy principle apply, and what outcomes at what scale are 
required?); and clarifying whether and under what circumstances out of kind exchanges would be permitted in relation to both principles (e.g. in achieving No Net Loss, or only once No Net Loss has been achieved in attaining Net Gain).

For consultants: paying particular attention to the specific outcomes required under either principle within time-frames required for each case and context, including exchange options, likely risks and uncertainties, optimum frames of reference, and choice of metrics.

For businesses: taking into account the frames of reference, time-frames and the range of uncertainties associated with pursuing either No Net Loss or Net Gain outcomes when deciding on policy, balancing the potential reputational benefits of the latter against the greater potential to be discredited.

For financial institutions: being more explicit about lending requirements, particularly in terms of the extra burden of proof upon achieving and being able to demonstrate defensibly a net positive rather than a net neutral outcome for biodiversity.

\section{Acknowledgements}

We thank Amrei von Hase, Bruce McKenney and Leon Bennun for insightful comments and constructive criticism during the discussion of this topic at the 2014 BBOP conference. JWB is supported by a Marie Skłodowska-Curie Fellowship award from the European Commission.

\section{References}

Apostolopoulou, E. \& Adams, W.M. (2016) Biodiversity offsetting and conservation: reframing nature to save it. Oryx, in press.

Baillie, J.E.M., Hilton-Taylor, C. \& Stuart, S.N. (eds) (2004) 2004 IUCN Red List of Threatened Species. A Global Species Assessment. Gland, Switzerland, and Cambridge, UK.

BAyon, R. \& Jenkins, M. (2010) The business of biodiversity. Nature, 466, 184-185.

BBOP (Business and Biodiversity Offsets Programme) (2012a) Standard on Biodiversity Offsets. BBOP, Washington, DC, USA.

BBOP (Business and Biodiversity Offsets Programme) (2012b) Resource Paper: No Net Loss and Loss-Gain Calculations in Biodiversity Offsets. BBOP, Washington, DC, USA.

BBOP (Business and Biodiversity Offsets Programme) (2014) To No Net Loss of Biodoversity and Beyond. Http://bbop. forest-trends.org/events/no-net-loss/ [accessed 2 August 2015].

BuLL, J.W. (2014) Biodiversity offsets for moving conservation targets. $\mathrm{PhD}$ thesis. Imperial College London, UK.

Bull, J.W., Suttle, K.B., Gordon, A., Singh, N.J. \& Milner-Gulland, E.J. (2013a) Biodiversity offsets in theory and practice. Oryx, 47, 369-380.

Bull, J.W., Suttle, K.B., Singh, N.J. \& Milner-Gulland, E.J. (2013b) Conservation when nothing stands still: moving targets and biodiversity offsets. Frontiers in Ecology and the Environment, 11, 203-210
Bull, J.W., Milner-Gulland, E.J., Suttle, K.B. \& Singh, N.J. (2014a) Comparing biodiversity offset calculation methods with a case study in Uzbekistan. Biological Conservation, 178, 2-10.

Bull, J.W., Gordon, A., Law, E.A., Suttle, K.B. \& Milner-Gulland, E.J. (2014b) Importance of baseline specification in evaluating conservation interventions and achieving no net loss of biodiversity. Conservation Biology, 28, 799-809.

BURGIN, S. (2008) BioBanking: an environmental scientist's view of the role of biodiversity banking offsets in conservation. Biodiversity and Conservation, 17, 807-816.

CBD (Secretariat of the Convention on Biological Diversity) (2010) Global Biodiversity Outlook 3. CBD, Montréal, Canada.

Curran, M., Hellweg, S. \& Beck, J. (2014) Is there any empirical support for biodiversity offset policy? Ecological Applications, 24, $617-632$.

Defra (Department for Environment, Food and Rural Affairs) (2011) Biodiversity Offsets: Guiding Principles for Biodiversity Offsetting. Defra, London, UK.

Ferraro, P.J. \& Pattanayak, S.K. (2006) Money for nothing? A call for empirical evaluation of biodiversity conservation investments. PLoS Biology, 4(4), e105.

Gardner, T.A., von Hase, A., Brownlie, S., Ekstrom, J.M.M., PILGRIM, J.D., SAVY, C.E. et al. (2013) Biodiversity offsets and the challenge of achieving no net loss. Conservation Biology, 27, $1254-1264$.

Gordon, A., Bull, J.W., Wilcox, C. \& Maron, M. (2015) Perverse incentives risk undermining biodiversity offset policies. Journal of Applied Ecology, 52, 532-537.

Gordon, A., Langford, W.T., Todd, J.A., White, M.D., Mullerworth, D.W. \& Bekessy, S.A. (2011) Assessing the impacts of biodiversity offset policies. Environmental Modelling \& Software, 26, 1481-1488.

Habib, T.J., Farr, D.R., Schneider, R.R. \& Boutin, S. (2013) Economic and ecological outcomes of flexible biodiversity offset systems. Conservation Biology, 27, 1313-1323.

IfC (International Finance Corporation) (2012) Performance Standard 6: Biodiversity Conservation and Sustainable Management of Living Natural Resources. IFC, Washington, DC, USA.

Jones, I.L., Bull, J.W., Milner-Gulland, E.J., Esipov, A.V. \& SutTLE, K.B. (2014) Quantifying habitat impacts of natural gas infrastructure to facilitate biodiversity offsetting. Ecology and Evolution, 4, 79-90.

Kujala, H., Burgman, M.A. \& Mollanen, A. (2013) Treatment of uncertainty in conservation under climate change. Conservation Letters, 6, 73-85.

Mace, G., Masundire, H. \& Baillie, J. (2005) Biodiversity. In Ecosystems and Human Well-being: Current State and Trends (eds R. Hassan, R. Scholes \& N. Ash), pp. 77-122. Millennium Ecosystem Assessment. Island Press, Washington, DC, USA.

Madsen, B., Carroll, N. \& Moore Brands, K. (2010) State of Biodiversity Markets Report: Offset and Compensation Programs Worldwide. Forest Trends, Washington, DC, USA.

Maron, M., Hobbs, R.J., Mollanen, A., Matthews, J.W., Christie, K., Gardner, T.A. et al. (2012) Faustian bargains? Restoration realities in the context of biodiversity offset policies. Biological Conservation, 155, 141-148.

Moilanen, A., Van Teeffelen, A.J.A., Ben-Haim, Y. \& Ferrier, S. (2009) How much compensation is enough? A framework for incorporating uncertainty and time discounting when calculating offset ratios for impacted habitat. Restoration Ecology, 17, 470-478.

Pickett, E.J., Stockwell, M.P., Bower, D.S., Garnham, J.I., Pollard, C.J., Clulow, J. \& Mahony, M.J. (2013) Achieving no net loss in habitat offset of a threatened frog required high offset 
ratio and intensive monitoring. Biological Conservation, 157, 156-162.

Poulton, D.W. (2014) Conservation offset policy for Alberta: a comparative legal analysis. MSc thesis. University of Calgary, Alberta, Canada.

Rainey, H.J., Pollard, E.H.B., Dutson, G., Eкstrom, J.M.M., Livingstone, S.R., Temple, H.J. \& Pilgrim, J.D. (2015) A review of corporate goals of No Net Loss and Net Positive Impact on biodiversity. Oryx, 49, 232-238.

Rajvanshi, A., Brownlie, S., Slootweg, R. \& Arora, R. (2011) Maximizing benefits for biodiversity: the potential of enhancement strategies in impact assessment. Impact Assessment and Project Appraisal, 29, 181-193.

Richert, C., Rogers, A. \& Burton, M. (2015) Measuring the extent of a Social License to Operate: the influence of marine biodiversity offsets in the oil and gas sector in Western Australia. Resources Policy, 43, 121-129.

ten Kate, K. \& Crowe, M.L.A. (2014) Biodiversity Offsets: Policy Options for Governments. An input paper for the IUCN Technical Study Group on Biodiversity Offsets. IUCN, Gland, Switzerland.
Tucker, G., Allen, B., Conway, M., Dickie, I., Hart, K., Rayment, M. et al. (2013) Policy Options for an EU No Net Loss Initiative. Report to the European Commission. Institute for European Environmental Policy, London, UK.

Walker, S., Brower, A.L., Stephens, R.T.T. \& Lee, W.G. (2009) Why bartering biodiversity fails. Conservation Letters, 2, 149-157.

\section{Biographical sketches}

JOSEPH BULL explores the outcomes of human activities in a range of ecosystems at macro-ecological scales, considering system change and uncertainties, through simulation modelling and spatial analyses. $\mathrm{He}$ has a particular research interest in the topic of business and biodiversity. SUSIE BROWNLIE has worked in the field of environmental assessment for over 30 years. Her core interest is in biodiversityinclusive impact assessment at strategic and project levels. She has been involved in the developing field of biodiversity offsets, has prepared policy and guidance, and has worked on specific offset projects. Her other interests are ecosystem services and social-ecological resilience as applied to environmental assessment and planning. 